\title{
PERENCANAAN PROGRAM 'INTERNET TERAPUNG' DALAM RANGKA PENYEBARLUASAN DAN PEMERATAAN INFORMASI BAGI MASYARAKAT KEPULAUAN
}

\section{The Planning of Boat-Cap in the Framework Equitable and Dissemination of Information for Maritime Communities}

\author{
${ }^{1}$ Nuur Widya Rahim, ${ }^{2}$ Hafied Cangara, ${ }^{3}$ Muh. Farid \\ ${ }^{1}$ Jurusan Ilmu Komunikasi, Fakultas Ilmu Sosial dan Ilmu Politik, \\ Universitas Hasanuddin, Makassar (widyrahim@gmail.com) \\ ${ }^{2}$ Jurusan Ilmu Komunikasi, Fakultas Ilmu Sosial dan Ilmu Politik, \\ Universitas Hasanuddin, Makassar (cangara_hafied@yahoo.com) \\ ${ }^{3}$ Jurusan Ilmu Komunikasi, Fakultas Ilmu Sosial dan Ilmu Politik, \\ Universitas Hasanuddin, Makassar (faridemsil@yahoo.com)
}

\begin{abstract}
ABSTRAK
Penelitian ini dilatarbelakangi oleh kesenjangan informasi yang terjadi antara penduduk yang tinggal di pulau-pulau dengan penduduk yang tinggal di daratan Kabupaten Pangkajene dan Kepulauan. Penelitian ini bertujuan untuk mengetahui dan menganalisis kelayakan pelaksanaan rencana program 'Internet Terapung' yang dicanangkan oleh Kementerian Komunikasi dan Informatika Republik Indonesia bagi masyarakat pulau-pulau dalam wilayah Kabupaten Pangkep dilihat dari aspek manfaat, faktor pendorong dan penghambat, serta kesiapan Pemerintah Daerah melaksanakan program tersebut. Penelitian ini menggunakan metode deskriptif kualitatif dengan pendekatan fenomenologi. Penelitian dilaksanakan di Kabupaten Pangkajene dan Kepulauan. Sumber data diperoleh dari hasil wawancara mendalam dari 23 orang informan, kemudian dianalisis dengan menggunakan pendekatan konsep perencanaan pembangunan infrastruktur komunikasi. Hasil penelitian menunjukkan bahwa program internet terapung layak untuk diaplikasikan di wilayah Kepulauan Kabupaten Pangkajene dan Kepulauan karena ada 87.931 jiwa dari 620.062 jiwa penduduk yang bertempat tinggal di pulau-pulau. Manfaat yang dapat diperoleh dari pelaksanaan program tersebut antara lain memenuhi kebutuhan pemerataan informasi untuk masyarakat dalam rangka meningkatkan kecerdasan dan kesejahteraan bagi masyarakat yang tinggal di pulau-pulau. Penelitian ini juga menyarankan bahwa untuk suksesnya program ini diperlukan regulasi sistem operasinalisasi yang berkesinambungan, untuk itu perhatian dan bantuan Pemerintah Daerah sangat diperlukan.
\end{abstract}

Kata kunci : Internet Terapung, Perencanaan Program, Masyarakat Kepulauan

\begin{abstract}
This research is motivated by information gap that occurs between people living on islands with populations living in mainland Pangkajene and Islands Regency. in the district of Pangkajene and Islands. This research aimed to determine and analyze feasibility planning application program that proclaimed 'Boat-CAP' Ministry of Communications and Informatics Republic of Indonesia for the community islands in the region within the district Pangkep an examination of the benefits, drivers and inhibitors, as well as the readiness of local authorities to implement the program. The research methods used were qualitative descriptive with phenomenology approach. The research was conducted in district of Pangkajene and Islands. Sources of data obtained from in-depth interviews of 23 informants and then analyzed using the concept of development planning approach to communications infrastructure. The result showed that the Boat-CAP Program eligible to apply in the archipelago Pangkajene Islands Regency because there are 87.931 inhabitants of 620.062 inhabitants residing in the islands. Benefits to be derived from the implementation of the program, among others meet the needs of even distribution of information to the public in order to improve intelligence and prosperity for the people living on the islands. The study also
\end{abstract}


suggests that for the success of this program is necessary regulatory operationalization system of sustainable, for the attention and help of local governments is crucial.

Keywords : Boat-CAP, Planning Program, Island Communities

\section{PENDAHULUAN}

Selama tahun 2000-an, internet telah memasuki fase yang disebut web 2.0 (web two point-oh), dimana semua menjadi lebih interaktif dan telah menjadi area untuk semua orang, tidak hanya milik beberapa pihak saja. Semua orang saat ini dapat langsung mengambil peran dan menaruh apapun ke dalam internet.

Internet memiliki kemampuan untuk mengkode, menyimpan, memanipulasi dan menerima pesan (Ruben, 1998). Internet tidak dimiliki, dikendalikan atau dikelola oleh sebuah badan tunggal tetapi merupakan sebuah jaringan komputer yang terhubung secara intensional dan beroperasi berdasarkan protokol yang disepakati bersama. Sejumlah organisasi khususnya provider dan badan telekomunikasi berperan dalam operasi internet (McQuail, 2009). Begitu banyak hal yang dapat dilakukan melalui internet/media baru. Hal ini dimungkinkan karena seperti dikatakan Feldman (Flew, 2004), media baru itu memiliki karakteristik : 1) manipulable (mudah diubah dan beradaptasi dalam setiap tahap pembuatan, penyimpanan, pengiriman dan penggunaan), 2) networkable (mudah dibagi dan dipertukarkan antara banyak pengguna secara bersamaan dan melewati jarak yang jauh sekaligus), 3) dense (jumlah informasi digital yang besar dapat disimpan dalam ruang fisik kecil), 4)compressible (kapasitas informasi dapat diringkas sesuai kebutuhan), dan 5) impartial (informasi digital mudah disebarkan jaringan tanpa peduli dalam bentuk apa informasi tersebut diwakilkan, siapa yang memiliki atau membuat informasi tersebut, atau untuk apa informasi tersebut akan digunakan. Karenanya, dengan melalui media baru masyarakat dapat memperoleh informasi dari seluruh dunia melalui berbagai situs yang terhubung dalam web. Selain itu masyarakat bisa saling berbagi informasi serta saling berkomunikasi melalui berbagai fasilitas yang terdapat di blog, email, instant messaging, serta situs jejaring sosial.

Kabupaten Pangkajene dan Kepulauan adalah salah satu kabupaten di Propinsi Sulawesi
Selatan, Indonesia. Terdiri dari tiga dimensi, yaitu : daratan, pegunungan dan kepulauan. Wilayahnya terdiri dari 13 kecamatan yang terbagi dalam 7 (tujuh) kecamatan di daratan, 2 (dua) kecamatan yang terletak di daerah pegunungan, dan 4 (empat) kecamatan pada wilayah kepulauan.

Sebagai salah satu daerah yang multidimensi, konsep penyebarluasan dan pemerataan informasi menjadi poin penting yang harus dilaksanakan dan menjadi prioritas bagi Pemerintah Kabupaten Pangkajene dan Kepulauan guna untuk memenuhi kebutuhan masyarakat akan pentingnya informasi. Namun, pada kenyataannya penyebarluasan dan pemerataan informasi belum mampu terealisasi.

Pangkajene dan Kepulauan sebagai kabupaten yang memiliki 4 (empat) kecamatan yang terletak di wilayah kepulauan memiliki hambatan komunikasi dalam mewujudkan konsep penyebarluasan dan pemerataan informasi. Terbatasnya jangkauan untuk wilayah kepulauan, menjadikan wilayah ini jarang tersentuh oleh pembangunan.

Sebagai kabupaten yang berorientasi pada kemajuan daerah, perkembangan teknologi informasi telah disadari mampu memberikan kontribusi yang cukup signifikan bagi perkembangan Kabupaten Pangkajene dan Kepulauan, sehingga pemerintah daerah dalam hal ini Dinas Perhubungan, Komunikasi dan Informatika berupaya untuk mengembangkan potensi daerah melaui pemanfaatan dan penyebarluasan informasi melalui internet untuk menyerap,

mengadakan dan mengimplementasikan teknolo gi melalui Internet tidak terkecuali untuk wilayah kepulauan. Dengan alasan tersebut, maka dibuatlah perencanaan Program 'Internet Terapung' ini. keberhasilan dari pelaksanaan program 'Internet Terapung' tentunya harus diawali dengan proses perencanaan yang baik.

Program 'Internet Terapung' tidak hanya fokus pada hasil yang ingin dicapai. Melainkan pula pada proses untuk mencapai hasil tersebut. Pencapaian tersebut tentunya tidak lepas dari 
proses awal dari pelaksanaan program 'Internet Terapung' ini yaitu pada tahap perencanaan. Proyek 'Internet Terapung' perlu direncanakan dengan matang sehingga layak untuk diimplementasikan. Olehnya itu, penulis tertarik untuk meneliti kelayakan pengaplikasian perencanaan program 'Internet Terapung' dan faktor-faktor yang mejadi pendorong dan penghambat pelaksanaan Program 'Internet Terapung' bagi masyarakat pulau-pulau dalam wilayah Kabupaten Pangkajene dan Kepulauan. Penelitian ini bertujuan untuk mengetahui dan menganalisis kelayakan pelaksanaan rencana program 'Internet Terapung' yang dicanangkan oleh Kementerian Komunikasi dan Informatika Republik Indonesia bagi masyarakat pulau-pulau dalam wilayah Kabupaten Pangkep dilihat dari aspek manfaat, faktor pendorong dan penghambat, serta kesiapan Pemerintah Daerah melaksanakan program tersebut.

\section{BAHAN DAN METODE}

Pada penelitian ini pendekatan yang dilakukan berupa pendekatan kualitatif, dengan maksud untuk memperoleh gambaran yang utuh atas informan penelitian sehingga dapat menjabarkan fokus penelitian tentang Perencanaan Program 'Internet Terapung' dalam rangka penyebarluasan dan pemerataan informasi bagi masyarakat kepulauan dalam wilayah Kabupaten Pangkajene dan Kepulauan.

Bogdan \& Taylor (1993), pendekatan kualitatif merupakan prosedur penelitian yang menghasilkan data deskriptif melalui pengungkapan kata-kata tertulis atau lisan dari orang-orang, peristiwa tertentu secara rinci dan mendalam serta perilaku yang diamati.

Beberapa pertimbangan seperti diuraikan Vredenberg dalam Alwasilah (2002) yang mendasarkan penggunaan pendekatan kualitatif dalam suatu penelitian antara lain : 1) penelitian kualitatif menyajikan bentuk yang menyeluruh (holistik) dalam menganalisas suatu fenomena; 2) penelitian jenis ini lebih peka menangkap informasi kualitatif deskriptif, dengan cara relatif tetap berusaha mempertahankan keutuhan (wholeness) dari obyek yang berarti bahwa data yang dikumpulkan dalam rangka studi kasus dipelajari sebagai keseluruhan yang terintegrasi.

\section{Lokasi dan Rancangan Penelitian}

Penelitian ini dilaksanakan pada Kantor

Dinas Perhubungan, Komunikasi dan Informatika Kabupaten Pangkajene dan Kepulauan. Obyek penelitiannya yaitu Sistem Perencanaan Program 'Internet Terapung' pada Dinas Perhubungan, Komunikasi dan Informatika Kabupaten Pangkajene dan Kepulauan. Program 'Internet Terapung' ini akan diaplikasikan oleh Kementerian Komunikasi dan Informatika melalui Dinas Perhubungan Komunikasi dan Informatika Kabupaten Pangkajene dan Kepulauan yang ditujukan untuk masyarakat yang bertempat tinggal di pulau-pulau dalam wilayah Kabupaten Pangkajene dan Kepulauan.

\section{Sumber Data}

Jenis data yang dikumpulkan terbagi atas dua, yaitu data primer dan data sekunder. Data primer primer merupakan data yang diperoleh secara langsung dari lokasi penelitian melalui wawancara dengan informan yang berkaitan dengan masalah penelitian, dan juga melaui observasi atau pengamatan langsung terhadap objek penelitian. Data sekunder adalah data yang diperoleh dalam bentuk uraian. Dalam penelitian ini data-data sekunder yang diperlukan antara lain : literature yang relevan dengan judul penelitian, misalnya materi atau dokumen-dokumen dari Dinas Perhubungan, Komunikasi dan Informatika Kabupaten Pangkajene dan Kepulauan serta buku-buku dan karya ilmiah yang relevan dengan penelitian.

\section{Teknik Pengumpulan Data}

Dalam penelitian kualitatif, pengumpulan data dilakukan pada natural setting (kondisi yang alamiah), sumber data primer, dan teknik pengumpulan data lebih banyak pada observasi, wawancara mendalam serta dokumentasi. Oleh karena itu, peneliti melakukan pengumpulan data dengan beberapa cara yaitu : bertemu langsung dengan informan, mengubungi informan via telepon, ataupun komunikasi dengan memanfaatkan beberapa media sosial yang ada seperti Whatsapp, Line, Blackberry Messenger, ataupun chatting via sms short messege service. 


\section{HASIL PENELITIAN}

Kabupeten Pangkajene dan Kepulauan, secara administratif terdiri dari 13 kecamatan, dimana 9 kecamatan terletak pada wilayah daratan dan 4 Kecamatan terletak di wilayah kepulauan. Penelitian ini dilaksanakan di Wilayah Kabupaten Pangkajene dan Kepulauan.

Kabupaten Pangkajene dan Kepulauan merupakan daerah yang memilki karakteristik tersendiri yakni keunikan wilayahnya yang terdiri dari tiga dimensi yaitu wilayah dataran rendah, wilayah dataran tinggi dan wilayah kepulauan. Dimana, masyarakatnya tersebar bermukim dan menghuni di tiga wilayah tersebut.

Hingga akhir tahun 2014, pada hasil Sensus Badan Pusat Statistik tahun 2014 menyatakan penduduk Kabupaten Pangkajene dan Kepulauan sekitar 620.062 Jiwa yang terdiri atas 299.201 Laki-laki dan 320.861Jiwa Perempuan dan tersebar di 13 kecamatan, dengan jumlah penduduk terbesar yakni 320.293 Jiwa yang terdapat pada Kecamatan Mandalle. Adapun kecamatan dengan jumlah penduduk paling sedikit adalah Kecamatan Balocci dengan jumlah penduduk 8.884 Jiwa. Adapun jumlah penduduk berdasarkan kecamatan di Kabupaten Pangkajene dan Kepulauan untuk Tahun 2014, sebagaimana digambarkan pada tabel 1 .

Berdasarkan data, dapat disimpulkan bahwa sebagian besar dari warga Kabupaten Pangkajene dan Kepulauan tinggal dan bermukim di wilayah kepulauan yaitu sebanyak 87.931 Jiwa dan ini merupakan angka yang cukup dinamis.

Diantara 4 (empat) kecamatan yang berada di wilayah kepulauan, terdapat 2 (dua) kecamatan yakni Kecamatan Liukang Kalukuang Masalima (Kalmas) dan Kecamatan Liukang Tangaya yang menjadi sasaran dari pelaksanaan program internet terapung karena keduanya merupakan daerah yang tidak memiliki akses informasi dan komunikasi sama sekali (nihil).

Instrumen penelitian ini adalah pedoman wawancara yang berisi pertanyaan yang terdiri dari Ketersediaan akses informasi dan Komunikasi di wilayah Kepulauan Kecamatan Liukang Kalmas dan Kecamatan Liukang Tangaya, gambaran program internet terapung, kelayakan program internet terapung, Manfaat program internet terapung dalam rangka penyebarluasan informasi dan pemerataan Informasi, Hambatan pelaksanaan program internet terapung, Faktor pendorong pelaksanaan program internet terapung, sumber anggaran program internet terapung dan kesiapan pemda dalam mensukseskan program internet terapung.

Jawaban yang dipeoleh dari daftar pertanyaan tersebut dikodekan berdasarkan kesamaan-kesamaan jawaban dari masingmasing penanggung jawab program internet terapung di lokasi penelitian yang selanjutnya dinarasikan sebagaimana mestinya penelitian kualitatif.

Internet terapung menggunakan kapal bertipe monohull sepanjang 15 meter, digeber mesin 1 x 115 hp mampu melesat 12 knot dengan komsumsi BBM cukup 18 liter per jam dilengkapi dengan 10 unit komputer di dalamnya dan diharapkan dapat menjangkau kawasan perairan terpencil di wilayah Kabupaten Pangkajene dan Kepulauan. Desain prototype dapat dilihat pada gambar 1 .

Untuk akses jaringan kapal ini dilengkapi dengan V-SAT (Very Small Aperture Terminal) yang merupakan stasiun penerima sinyal dari satelit dengan antenna penerima berbentuk piringan dengan diameter kurang dari 3 meter. Fungsi utama V-SAT adalah untuk menerima dan mengirim data ke satelit.

\section{PEMBAHASAN}

Hasil dari penelitian ini menemukan bahwa program ini sebetulnya mulai digagas oleh Kementerian Komunikasi dan Informatika pada Tahun 2012 yang lalu. Namun, saat ini baru 1 (satu) daerah yang berhasil dalam mengaplikasikan program ini yaitu Propinsi Kalimantan Selatan. Program yang dirancang ini sebagai percobaan atau sebagai pilot-project untuk daerah yang memiliki wilayah perairan. Hal ini yang kemudian coba dilakukan juga oleh Dinas Perhubungan Komunikasi dan Informatika Kabupaten Pangkajene dan Kepulauan sebagai salah satu daerah yang juga terdiri dari wilayah perairan dan kepulauan. Sehingga, pada Tahun 2015 lalu, Dinas Perhubungan Komunikasi dan Informatika juga telah melakukan launching program internet terapung dan cukup mendapatkan antusias dari warga yang hadir pada acara tersebut yang merupakan masyarakat kepulauan. 
Namun, tidak dapat dipungkiri dari beberapa informan yang dimintai keterangannya sebagian dari mereka ada yang belum mengetahui dan memahami penggunaan aplikasi dan manfaat dari internet terapung ini. Meskipun, telah dilakukan sosialisasi oleh pihak pengelola program. Tentunya ini bukan merupakan suatu hal yang mudah bagi pemerintah, butuh waktu dan kesabaran. Pemerintah harus lebih aware lagi dalam memberikan support kepada masyarakat, bukan hanya dalam bentuk kesediaaan menyediakan sarana dan prasarana, tapi juga kesiapan pemerintah dalam bentuk support anggaran untuk biaya operasional dan pemeliharaannya demi keberhasilan dan keberlangsungan dari program internet terapung ini. Hal ini sejalan dengan yang diungkapkan oleh Rogers (1983), bahwa dalam proses difusi inovasi terdapat 4 (empat) elemen pokok, yaitu : suatu inovasi, dikomunikasikan melalui saluran komunikasi tertentu, dalam jangka waktu tertentu dan terjadi di antara anggota-anggota suatu sistem sosial.

Hasil penelitian menunjukkan bahwa ada banyak manfaat yang dapat diperoleh dari pelaksanaan program internet terapung yaitu untuk memenuhi kebutuhan masyarakat kepulauan akan akses informasi dan komunikasi dalam rangka mewujudkan penyebarluasan dan pemerataan informasi di wilayah Kabupaten Pangkep. Seperti yang dikemukakan oleh Achmad (1990) kata "sebaran" dalam berita mengandung dua pengertian, yaitu pertama adalah menyebar dan yang kedua adalah tersebar. Pengertian menyebar merujuk pada suatu kegiatan, sedangkan pengertian tersebar merujuk pada hasil atau akibat dari suatu kegiatan. New Media atau media online didefenisikan sebagai produk dari komunikasi yang termediasi teknologi yang terdapat bersama dengan komputer digital (Creeber \& Martin, 2009). Defenisi lain media online adalah media yang di dalamnya terdiri dari gabungan berbagai elemen. Itu artinya terdapat konvergensi media di dalamnya, dimana beberapa media dijadikan satu (Lievrouw, 2011). New Media merupakan media yang menggunakan internet, media online berbasis teknologi, berkarakter fleksibel, berpotensi interaktif dan dapat berfungsi secara privat maupun secara public (Mondry, 2008). Defenesi tersebut sejalan dengan hasil penelitian yang menunjukkan bahwa internet mampu melayani warga kepulauan yang membutuhkan akses internet layaknya masyarakat di kota sehingga tidak ada lagi wilayah di Kabupaten Pangkajene dan Kepulauan yang tidak memiliki akses informasi, menggampangkan pengiriman informasi baik dari daratan ke kepulauan ataupun sebaliknya, untuk mendapatkan referensi bahan pembelajaran yang dapat menunjang kinerja dan kelancaran proses belajar mengajar bagi guru dan siswa di wilayah kepulauan dan bagi para nelayan dan pedagang memanfaatkannya untuk memasarkan hasil-hasil tangkapan ikan di laut melalui situs online, memanfaatkan segala potensi hasil laut sebagai komoditas yang dapat menjadi sumber penghasilan bagi mereka. Program Internet Terapung ini atau Boat-Cap dapat dipergunakan untuk sarana pelayanan publik seperti Sistem Informasi Satu Atap (SINTAP). Masyarakat dapat memanfaatkannya untuk mendapatkan pelayanan-pelayanan publik seperti : mengurus Izin Mendirikan Banguan, Akte Kelahiran dan berbagai dokumen penting lainnya

Sebagaimana yang dikatakan oleh Feldman dalam Flew (2004), begitu banyak hal yang dapat dilakukan melalui internet/media baru. Media baru itu memiliki karakteristik : 1) manipulable (mudah diubah dan beradaptasi dalam setiap tahap pembuatan, penyimpanan, pengiriman dan penggunaan), 2) networkable (mudah dibagi dan dipertukarkan antara banyak pengguna secara bersamaan dan melewati jarak yang jauh sekaligus), 3) dense (jumlah informasi digital yang besar dapat disimpan dalam ruang fisik kecil), 4) compressible (kapasitas informasi dapat diringkas sesuai kebutuhan), dan 5) impartial (informasi digital mudah disebarkan jaringan tanpa peduli dalam bentuk apa informasi tersebut diwakilkan, siapa yang memiliki atau membuat informasi tersebut, atau untuk apa informasi tersebut akan digunakan. Karenanya, dengan melalui internet masyarakat dapat memperoleh informasi dari seluruh dunia melalui berbagai situs yang terhubung dalam web.

Perihal mekanisme penganggaran operasional program internet terapung di Kabupaten Pangkajene dan Kepulauan dari hasil penelitian menunjukkan bahwa belum ada kejelasan siapa sebenarnya yang diwajibkan 
untuk membiayai operasionalisasi program internet terapung.

Hasil penelitian juga menunjukkan program internet terapung memiliki hambatan yang cukup signifikan, pada saat Kementerian Komunikasi dan Informatika Republik Indonesia melakukan koordinasi dengan para Kepala Daerah, yang dipertimbangkan adalah salah satunya terkait dengan kesiapan Pemerintah Daerah setempat untuk biaya pemeliharaan, karena biasanya Kementerian Komunikasi dan Informatika Republik Indonesia memberikan anggaran pemeliharaan hanya untuk 1 (satu) tahun. Setelahnya kemudian ditanggung oleh Pemerintah Daerah setempat. Seperti : Biaya Operator, Bahan Bakar Kapal, dan Pemeliharaan satelit. Berdasarkan hasil wawancara, Pemerintah Daerah menyatakan siap mensupport tapi belum ada kejelasan bentuk dukungan yang diberikan pemerintah daerah setempat.

\section{KESIMPULAN DAN SARAN}

Berdasarkan hasil analisis dari perencanaan program internet terapung, dapat disimpulkan bahwa aplikasi dari program internet terapung layak untuk diaplikasikan di wilayah Kepulauan Kabupaten Pangkep. Adapun manfaat dari terlaksananya program internet terapung bagi masyarakat kepulauan di wilayah Kabupaten Pangkep diantaranya adalah untuk memenuhi kebutuhan masyarakat akan akses informasi dan komunikasi dalam rangka mewujudkan penyebarluasan dan pemerataan informasi di wilayah Kabupaten Pangkajene dan Kepulauan, mengenai kesiapan Pemerintah Daerah, Bupati dan Wakil Bupati Pangkajene dan Kepulauan melalui hasil wawancara menyatakan kesiapannya dalam mendukung suksesnya pembangunan sarana informasi dan komunikasi di wilayah Kabupaten Pangkajene dan Kepulauan. Adapun sarannya, sebaiknya Pihak Dinas Perhubungan Komunikasi dan Informatika membuat berupa surat keputusan yang ditangani oleh pemangku kebijakan daerah setempat terkait pengelola program. Bagi para pemangku kebijakan, agar mendukung program ini sehingga tidak ada lagi wilayah di Kabupaten
Pangkajene dan Kepulauan yang mengalami kesenjagan digital dan keterbatasan akses informasi dan komunikasi. diharapkan pihak pengelola program dapat merekrut tenaga yang handal dan memiliki kompetensi serta profesinalisme dalam bidang teknologi informasi dan komunikasi. Bagi pengelola program internet terapung, agar menggelar pelatihanpelatihan teknis bagi masyarakat kepulauan terkait penggunaan internet dan melakukan kerja sama dengan para stakeholder di wilayah kepulauan demi keberhasilan dan keberlanjutan dari program.

\section{DAFTAR PUSTAKA}

Achmad. (1990). Manusia dan Informasi. Ujung Pandang : Hasanuddin University Press.

Alwasilah. (2002). Pokoknya Kualitatif, Dasardasar Merancang dan Melakukan Penelitian Kualitatif. Jakarta : PT. Kiblat Buku Utama.

Bogdan \& Taylor. (1993). Introduction in Qualitative Research Methods. New York : Weley.

Creeber \& Martin. (2009). Digital Cultures : Understanding New Media. BerkshireEngland : Open University Press.

Flew. (2004). An Introduction to New Media $2^{\text {nd }}$ Edition. pp.3. Source : http ://www.internetworldstats.com/top20.htm.

Lievrouw. (2011). Alternative and Activist New Media. Malden. MA : Polity Press.

McQuail. (2009). Mass Communication Theory, $5^{\text {th }} e d$. Los Angeles, Calif.[u.a]. : Sage.

Mondry. (2008). Pemahaman Teori dan Praktek Jurnalistik. Bogor : Ghalia Indonesia.

Rogers E.M. (1983). Diffusion of Innovation, 1th $e d$. New York : The First and Division of MacMilan Publishing.

Ruben. (1998). Communication and Human Behavior, $4^{\text {th }} \mathrm{ed}$. USA : Viacom Company. 


\section{LAMPIRAN}

Tabel 1. Jumlah Penduduk Per Kecamatan

di Kabupaten Pangkajene dan Kepulauan

Tahun 2014

\begin{tabular}{lrrr}
\hline \multicolumn{1}{c}{ Kecamatan } & $\begin{array}{c}\text { Laki-laki } \\
\text { (Jiwa) }\end{array}$ & $\begin{array}{c}\text { Penduduk } \\
\text { Perempuan } \\
\text { (Jiwa) }\end{array}$ & $\begin{array}{c}\text { Jumlah } \\
\text { (Jiwa) }\end{array}$ \\
\hline Wilayah Kepulauan & & & \\
Liukang Tangaya & 6.563 & 6.857 & 13.420 \\
Liukang Kalmas & 9.374 & 9.619 & 18.993 \\
Liukang Tupabbiring & 5.571 & 5.974 & 11.545 \\
Liukang Tupabbiring Utara & 21.315 & 22.658 & 43.973 \\
Wilayah Daratan & & & \\
Pangkajene & 16.857 & 18.047 & 34.904 \\
Minasatene & 7.800 & 8.122 & 15.922 \\
Balocci & 4.330 & 4.554 & 4.884 \\
Tondong Tallasa & 20.549 & 21.282 & 45.415 \\
Bungoro & 21.336 & 24.079 & 30.519 \\
Labakkkang & 14.605 & 15.914 & 19.900 \\
Ma'rang & 9.476 & 10.424 & 14.463 \\
Segeri & 6.817 & 7.646 & 320.293 \\
Mandalle & 154.608 & 165.685 & $\mathbf{6 2 0 . 0 6 2}$ \\
Total & & & \\
\hline
\end{tabular}

Sumber : Data BPS, Tahun 2014 
Gambar 1. Desain Prototype BOAT-CAP

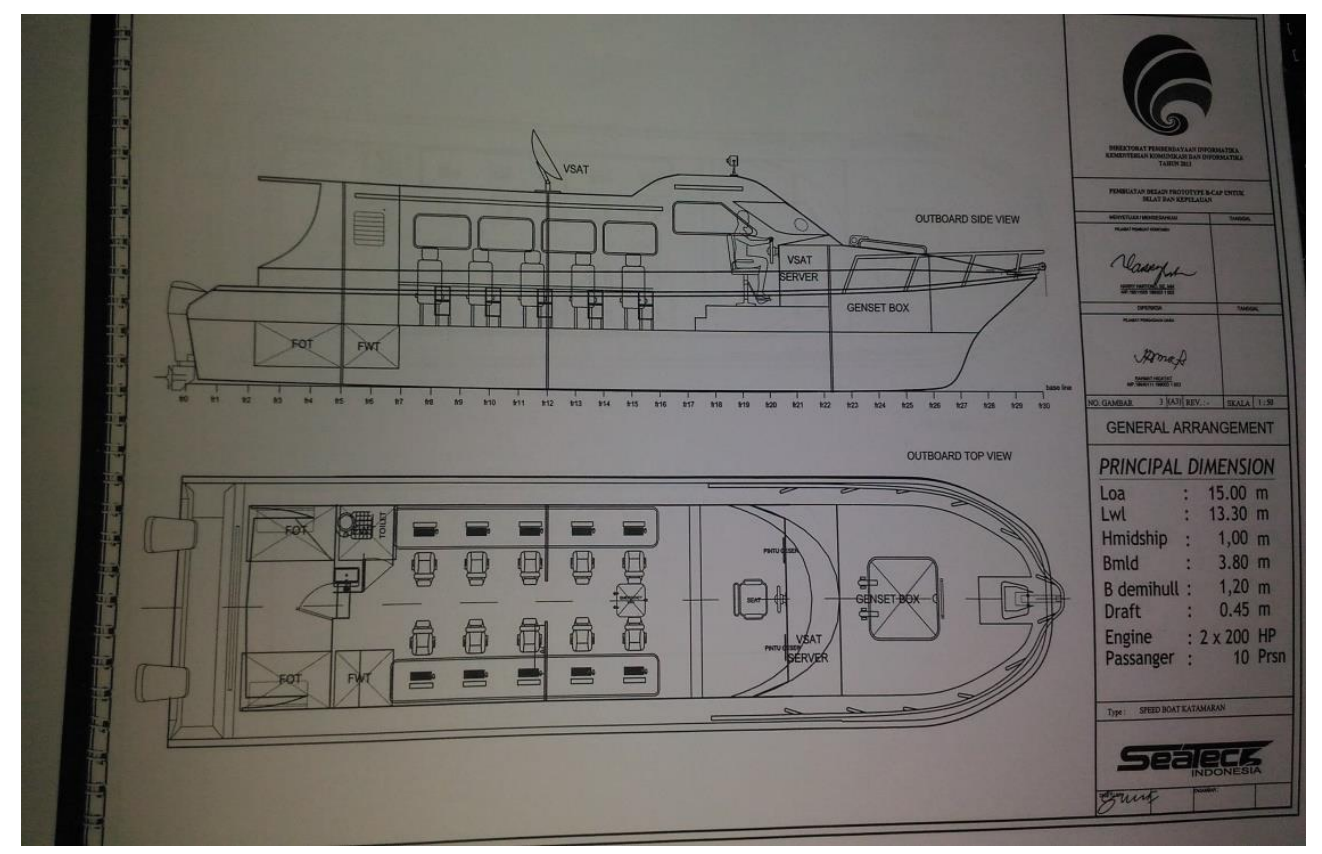

Sumber : Kemkominfo, Tahun 2012 